\title{
Effect of semen storage on the number of spermatozoa in the perivitelline layer of laid turkey eggs
}

\author{
A. M. Donoghue, M. R. Bakst, D. R. Holsberger and \\ D. J. Donoghue*
}

Germplasm and Gamete Physiology Laboratory, Agricultural Research Service, US Department of Agriculture, Beltsville, MD 20705, USA

\begin{abstract}
A progressive decline in fertility over the course of egg production may be observed when turkey hens are inseminated weekly with semen stored for $24 \mathrm{~h}$. In vitro storage of spermatozoa before insemination results in lower fertilization, possibly because fewer spermatozoa survive selection and storage in the hen's sperm storage tubules in vivo; alternatively, stored spermatozoa may be as capable of reaching the egg as are fresh spermatozoa, but unable to penetrate and fertilize the egg normally. The objective of this study was to determine whether this decline in fertility is a result of fewer spermatozoa reaching the egg after insemination with spermatozoa stored in vitro. Hens were inseminated weekly over the first 12 weeks of egg production with either fresh semen ( $n=30$ hens) or semen stored for $24 \mathrm{~h}(n=30$ hens). A total of 301 eggs was evaluated by determining the density distribution of spermatozoa embedded in the outer perivitelline layer. For the 12 weeks of egg production, the fertility of hens inseminated with fresh semen remained greater than $94 \%$. Conversely, the percentage fertility of eggs from hens inseminated with stored semen in weeks $1-3$ was greater than $94 \%$ but thereafter fertility averaged $86 \%$. There was no difference in hatchability of fertile eggs between the two treatments over all weeks combined, and weekly throughout the study $(P>0.05)$. The mean number of spermatozoa in the perivitelline layer was higher $(P<0.001)$ when hens were inseminated with fresh ( $12.1 \pm 1.3$ spermatozoa per $5.5 \mathrm{~mm}^{2}$ membrane) versus stored semen ( $2.5 \pm 0.3$ spermatozoa per $5.5 \mathrm{~mm}^{2}$ membrane) over all weeks combined, and weekly throughout the study $(P<0.05)$. As a result of storage for $24 \mathrm{~h}$, fewer spermatozoa are stored in the sperm storage tubules and, consequently, fewer spermatozoa are present at the site of fertilization, thus contributing to the depressed fertility.
\end{abstract}

\section{Introduction}

Significant progress has been made in understanding the physiological mechanisms that control sperm selection and storage in the oviduct of the turkey hen (Brillard and Bakst, 1990; Bakst, 1992, 1993; Brillard 1992; Bakst et al., 1994). Many factors influence the efficiency of sperm storage and subsequent fertility, including the timing of insemination (Christensen and Johnston, 1977; McIntyre and Christensen, 1985), the duration of egg production (Brillard, 1993) and the age of the hens (Van Krey et al., 1967). Artificial insemination (AI) before the onset of egg production maximizes the filling rate of the sperm storage tubules (SST) and results in higher fertility over the egg production period (McIntyre and Christensen, 1985). In addition, inseminations performed just before or after oviposition result in a decreased fertility

*Present address: Pharmacology-Biochemistry Branch, FDA, Beltsville, MD 20705, USA.

Received 22 May 1995. rate, possibly due to reduced numbers of spermatozoa in the SST (Christensen and Johnston, 1977). Fertility also declines over the egg production period after insemination with semen stored in vitro for $24 \mathrm{~h}$ (see review, Thurston, 1995). However, the effect of storage for $24 \mathrm{~h}$ in vitro on oviductal sperm storage and subsequent fertility is not fully understood.

Wishart (1987) developed a noninvasive bioassay that can provide an estimate of the duration of fertility of individual hens based on the density of spermatozoa embedded in the outer perivitelline layer of laid eggs. There is a significant positive correlation between the number of spermatozoa in the perivitelline layer and the number of spermatozoa residing in the SST at the time the egg is laid (Brillard and Antoine, 1990; Brillard and Bakst, 1990).

In this study, the perivitelline sperm counting procedure was used to determine whether the decline in fertility of hens inseminated with semen stored for $24 \mathrm{~h}$ is associated with fewer spermatozoa interacting with the ovum at the time of fertilization. 


\section{Materials and Methods}

\section{Animals and semen collection}

Commercial Large White breeder turkey tom and hen poults were purchased from a primary breeder and maintained under standard husbandry conditions during their brooding and growing periods. Toms and hens were photostimulated (03:00-17:00 h) at 26 and 28 weeks of age, respectively. Semen was first collected manually from toms at 28 weeks and, thereafter, at least once a week using two cloacal strokes (Bakst and Cecil, 1983). Semen from 5-10 toms was pooled and diluted 1:1 with turkey semen diluent (SemAid; Poultry Health Laboratories, Davis, CA) within 30 min of collection.

\section{Semen storage and preparation for insemination}

Diluted semen was divided into two aliquots, one part used for insemination within $90 \mathrm{~min}$ of collection (fresh), and the other part stored for $24 \mathrm{~h}$ and then used for insemination (stored). For storage, semen aliquots were kept in $10 \mathrm{ml}$ Erlenmeyer flasks covered loosely with foil. These flasks were placed in beakers containing enough water to reach the upper level of semen in the flask and the beakers were placed on an orbital shaker ( 150 r.p.m.) in a refrigerator at $5^{\circ} \mathrm{C}$ (Sexton, 1988).

Hens were inseminated initially on days 14 and 16 after the onset of photostimulation and once a week thereafter for the next 12 weeks with $150 \times 10^{6}$ viable spermatozoa. The percentage of viable spermatozoa was determined using the modified ethidium bromide exclusion procedure (Bakst et al., 1991). The insemination dose was adjusted accordingly to include a constant number of viable spermatozoa with each insemination. Two treatment groups consisting of 30 hens per group were established and inseminated with fresh or stored semen. Fifteen hens from each group were designated as egg donors for the evaluation of the number of spermatozoa in the perivitelline layer. Eggs from the remaining hens and those not used in the perivitelline bioassay were set once a week, candled at day $7-10$ and then incubated to determine hatchability.

\section{Quantification of spermatozoa in the perivitelline layer}

Eggs laid by hens designated for determination of the perivitelline sperm counting procedure were collected four times a day and examined within $12 \mathrm{~h}$ of collection. After removing adherent albumen, a piece of perivitelline membrane about $15 \mathrm{~mm} \times 25 \mathrm{~mm}$ was isolated and stained by the method of Wishart (1987) and modified using $5 \mu \mathrm{g}$ Hoeschst $33342 \mathrm{ml}^{-1}$ (Sigma, St Louis, MO; see Brillard and Bakst, 1990, for details). Spermatozoa in 50 randomly selected fields were counted at $\times 40$ magnification. The ovum was assumed fertile if $>2$ spermatozoa per $5.5 \mathrm{~mm}^{2}$ membrane were observed (Wishart, 1987).

\section{Statistical analysis}

Differences among the number of spermatozoa in the perivitelline layer, fertility and hatchability between hen groups were examined using analysis of variance (ANOVA) using the least squares procedure and the general linear models procedure of the Statistical Analysis System (SAS, 1985). Percentage data were arcsine transformed before analysis. Data are displayed as arithmetic means for clarity of presentation.

\section{Results}

A total of 301 eggs was evaluated to determine the number of spermatozoa trapped in the perivitelline layer over the first 11 weeks of egg production. For both fresh and stored semen treatments, the average number of eggs evaluated was 14 per week per treatment and ranged from 4 to 22 eggs. Results obtained at 12 weeks were not included in the data set because fewer than four eggs were available from the stored semen treatment group.

The number of spermatozoa in the perivitelline layer was higher $(P<0.05)$ by week for fresh versus stored semen treatments throughout the 11 week evaluation period (Fig. 1) and over all weeks combined, $12.1 \pm 1.3$ spermatozoa per $5.5 \mathrm{~mm}^{2}$ membrane for fresh and $2.5 \pm 0.3$ spermatozoa per $5.5 \mathrm{~mm}^{2}$ membrane for stored treatments, respectively $(P<0.001)$. Although the number of spermatozoa in the perivitelline layer varied greatly within the fresh treatment group (range 0-83 spermatozoa per $5.5 \mathrm{~mm}^{2}$ membrane), the mean number of spermatozoa in the perivitelline layer for stored semen (range 0-25 spermatozoa per $5.5 \mathrm{~mm}^{2}$ membrane) never reached the mean number of spermatozoa observed in the fresh treatment group (Fig. 1).

Candling fertility remained high throughout the egg production period in hens inseminated with fresh semen (Table 1). There was no difference in the fertility of eggs from hens inseminated with fresh and stored spermatozoa for the first 3 weeks of egg production. Thereafter, fertility was lower for hens inseminated with stored semen (Table $1 ; P<0.001$ ). Estimated fertility (determined by counting perivitelline spermatozoa) was similar $(P>0.05)$ to true fertility (determined by candling) for the eggs from hens inseminated with fresh spermatozoa ( $94.8 \%$ estimated fertile versus $96.7 \%$ fertile, respectively). For hens inseminated with stored spermatozoa,

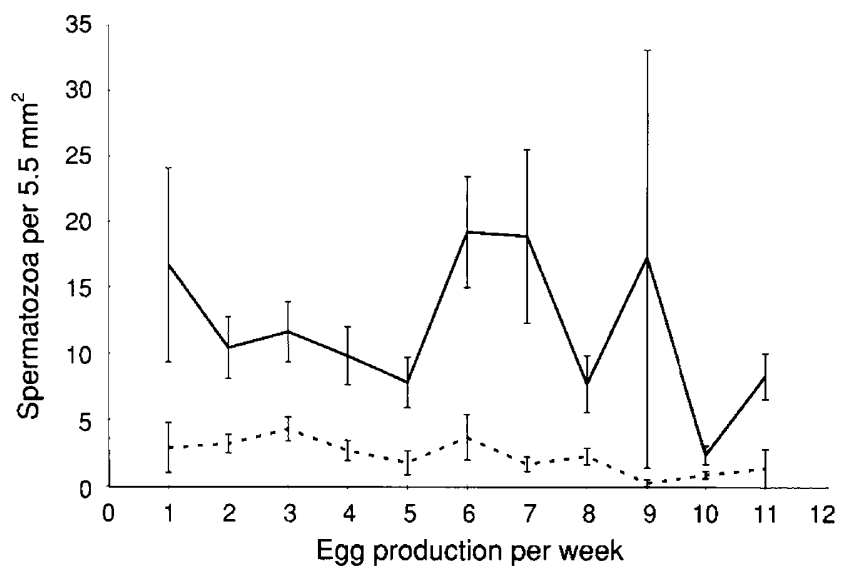

Fig. 1. Number of spermatozoa in the perivitelline layer (mean \pm SEM) of eggs laid from turkey hens inseminated with fresh semen $(-$ or semen stored for $24 \mathrm{~h} \mathrm{(--} \mathrm{).}$ 
Table 1. Percentage of turkey hen fertility $(\bar{x} \pm \mathrm{SEM})$ after weekly inseminations of semen before (fresh) or after $24 \mathrm{~h}$ storage at $5^{\circ} \mathrm{C}^{*}$

\begin{tabular}{lcccc}
\hline & \multicolumn{4}{c}{ Egg production period (weeks) } \\
\cline { 2 - 5 } Treatment & $1-3$ & $4-6$ & $7-9$ & $10-12$ \\
\hline Fresh & $97.9 \pm 0.5^{\mathrm{a}}$ & $95.7 \pm 0.6^{\mathrm{a}}$ & $96.1 \pm 0.6^{\mathrm{a}}$ & $97.0 \pm 0.6^{\mathrm{a}}$ \\
Stored & $95.0 \pm 0.7^{\mathrm{a}}$ & $85.6 \pm 1.0^{\mathrm{b}}$ & $86.5 \pm 1.1^{\mathrm{b}}$ & $87.4 \pm 1.1^{\mathrm{b}}$ \\
\hline
\end{tabular}

* Based on least square means of arcsine transformed data.

Means within columns with different subscripts are significantly different $(P<0.001)$.

Table 2. Percentage hatchability ( $\bar{x} \pm$ SEM) of fertile eggs after weekly inseminations of turkey hens with spermatozoa before (fresh) or after $24 \mathrm{~h}$ storage at $5^{\circ} \mathrm{C}^{*}$

\begin{tabular}{lcccc}
\hline & \multicolumn{4}{c}{ Egg production period (weeks) } \\
\cline { 2 - 5 } Treatment & $1-3$ & $4-6$ & $7-9$ & $10-12$ \\
\hline Fresh & $88.5 \pm 0.5$ & $89.7 \pm 1.1$ & $80.0 \pm 1.6$ & $86.8 \pm 1.5$ \\
Stored & $93.2 \pm 1.0$ & $88.0 \pm 1.7$ & $80.7 \pm 1.7$ & $88.3 \pm 1.4$ \\
\hline
\end{tabular}

*Based on least square means of arcsine transformed data. There were no significant differences between treatments with fresh and stored spermatozoa.

estimated fertility $(71.5 \%)$ was lower than true fertility $(88.5 \%$, $P<0.05$ ). Although the total number of hatched eggs was lower in the group treated with stored semen owing to decreased fertility, hatchability of fertile eggs between the fresh and stored treatments did not differ (Table 2).

\section{Discussion}

The mean number of spermatozoa in the perivitelline layer after insemination with stored spermatozoa was consistently lower than the number observed after insemination with fresh spermatozoa over the egg production period. Given that it has been clearly shown that there is a significant positive correlation between the number of spermatozoa in the perivitelline layer and the number residing in the SST (Brillard and Bakst, 1990; Brillard, 1992), our observations indicate that the depressed fertility observed in hens inseminated with spermatozoa stored for $24 \mathrm{~h}$ in vitro is due, in part, to fewer spermatozoa residing in the SST. The perivitelline layer bioassay (estimating the numbers of spermatozoa on laid eggs) has been used by several investigators as an indirect measure of efficiency of selection and storage in vivo in the SST in chickens (Brillard and Antoine, 1990; Alexander et al., 1993; Wishart et al., 1993; Wishart and Staines, 1995). Therefore, in the present study, the lower number of spermatozoa observed in the perivitelline layer of turkey eggs infers that selection and storage in vivo is compromised after sperm storage in vitro.

While hen fertility has been used as a final indicator of viability after storage for $24 \mathrm{~h}$, the real problem is not the inability of spermatozoa to reach the ovum but an inability of spermatozoa to survive the oviductal selection and storage process. Our results show a decline in fertility after the first 3 weeks of egg production in hens inseminated with stored semen. This decline has been demonstrated repeatedly when semen stored for $24 \mathrm{~h}$ is used (Sexton, 1988; Bakst et al., 1991). Egg production and fertility decrease over the egg production period in hens even when fresh semen is used for insemination (Van Krey et al., 1967; Brillard, 1993). Since hens are most efficient in producing fertile eggs at the beginning of egg production, the effect of using semen stored in vitro may not become apparent until several weeks into the production period.

In evaluating different flocks of naturally mated chickens using this bioassay, Wishart and Staines (1995) found that, in flocks with the highest fertility, the number of spermatozoa in the perivitelline layer was greater and there was a larger range in the numbers of spermatozoa on eggs evaluated $(0->600)$ compared with a flock with lower fertility, in which most of the eggs evaluated had less than 20 spermatozoa. They reasoned that the bioassay is a better predictor of hen fertility than evaluation of day to day fertility, because it gives a better insight into the overall efficiency of hens to store spermatozoa and produce fertile eggs. Similar to the findings of Wishart and Staines (1995) of the relationship between flock fertility and numbers of spermatozoa trapped in the perivitelline layer, we found more and a much greater range in number of spermatozoa in the perivitelline layer of eggs from hens inseminated with fresh semen (range, 0-83 spermatozoa per $5.5 \mathrm{~mm}^{2}$ membrane; average, 12 spermatozoa per $5.5 \mathrm{~mm}^{2}$ membrane) compared with eggs from hens inseminated with spermatozoa stored for $24 \mathrm{~h}$ (range, 0-25 spermatozoa per $5.5 \mathrm{~mm}^{2}$ membrane; average, 2.5 spermatozoa per $5.5 \mathrm{~mm}^{2}$ membrane). Hens inseminated with fresh semen appear to have a greater 
'reserve' of spermatozoa to ensure fertilization. In contrast, in hens inseminated with spermatozoa stored in vitro, there are only enough spermatozoa reaching the perivitelline layer to result in fertilization. Without any 'reserve spermatozoa', if fertilization is compromised in any way (i.e. by reduced sperm storage or lower sperm competence), hen fertility is lower.

There are several reasons why the efficiency of storage in the SST is lower after insemination with spermatozoa stored for $24 \mathrm{~h}$. There is normally an intense selection pressure in the vagina. Considering that only about $1-2 \%$ of fresh, inseminated spermatozoa are stored in the SST (Brillard and Bakst, 1990), semen storage for $24 \mathrm{~h}$ may further reduce the ability of spermatozoa to survive this selection process. Reducing the number of competent spermatozoa inseminated even further (by in vitro storage) could result in an even smaller population of spermatozoa stored in vivo and capable of fertilization. This is evident in the present study, in which $80 \%$ fewer spermatozoa were observed on the perivitelline layer of eggs inseminated with spermatozoa stored for $24 \mathrm{~h}$ compared with fresh semen.

Storage of spermatozoa in vitro has been shown to reduce sperm viability (Bakst and Cecil, 1991). Although most semen evaluation tests do not reveal 'weak' spermatozoa after $24 \mathrm{~h}$ storage, hypo-osmotic stress tests have shown that the number of spermatozoa with poor plasmalemma integrity is greatly increased after storage (Bakst and Cecil, 1991; Donoghue et al., 1995). Inseminating numbers of viable spermatozoa (after adjustment for sperm damage using the hypo-osmotic stress test) comparable to those in fresh semen does not prevent the fertility decline observed with stored semen (Bakst and Cecil, 1991). There is evidence that plasmalemma-associated proteins or glycoproteins are important components that allow spermatozoa to be stored in the SST (see reviews, Wishart and Steele, 1990; Bakst et al, 1994). When neuraminidase was used to cleave neuraminic acids of plasmalemma-associated proteins in chicken spermatozoa, storage in the SST was reduced after intravaginal insemination but not intrauterine insemination (Froman and Thurston, 1984; Steele, 1992). Storage in vitro may alter the surface characteristics of the plasmalemma, or intrinsic proteins associated with the plasmalemma, of a greater proportion of spermatozoa, decreasing the number that survive selection through the vagina. Thus, selection and spermatozoa viability in vivo may contribute to lower numbers of spermatozoa available to fertilize eggs after in vitro holding.

Insemination before the onset of egg production fills the SST and it is thought that subsequent weekly inseminations replace spermatozoa that have been released from the SST (Bakst and Cecil, 1991; Bakst et al., 1994). Since the reservoir of spermatozoa is initially lower with insemination of semen stored in vitro (based on a four times lower number of spermatozoa in the perivitelline layer of eggs from stored versus fresh semen inseminations), it is possible that the reduced fertility observed after the first 3 weeks of egg production for this treatment is due to the quantitative loss of spermatozoa in the SST and the lower efficiency of spermatozoa stored in vitro to replace them.

Our data on spermatozoa associated with the turkey perivitelline layer are similar to results observed with chickens (Wishart, 1987; Brillard and Antoine, 1990; Wishart et al, 1993). Wishart (1987) reported that only 2.0 spermatozoa per $5.5 \mathrm{~mm}^{2}$ were necessary to produce a fertile chicken egg.
Brillard and Antoine (1990) similarly found that 2.4 spermatozoa per $5.5 \mathrm{~mm}^{2}$ were needed to predict $100 \%$ flock fertility. In the present study, 2 or more spermatozoa per $5.5 \mathrm{~mm}^{2}$ were observed in the perivitelline layer of about $95 \%$ of all eggs from hens inseminated with fresh semen, which was similar to the overall candling fertility $(96.7 \%)$. In contrast, after insemination with semen stored for $24 \mathrm{~h}$, fertility estimates for eggs evaluated for perivitelline layer spermatozoa number was lower than that observed for candled eggs $(71.5 \%$ versus $88.5 \%$, respectively). Since fewer spermatozoa are observed in the perivitelline layer after storage of semen in vitro and the average number observed (2.5 spermatozoa per $5.5 \mathrm{~mm}^{2}$ ) is closer to Wishart's cut-off point for estimating fertility in chickens, it is possible that some eggs could be incorrectly considered infertile because so few spermatozoa are embedded in the perivitelline layer and are therefore missed when only a portion of the perivitelline layer is assessed. In contrast, the numbers of spermatozoa in the perivitelline layer for fresh semen averaged 2-40-fold higher; therefore, it is more likely that assessment of membrane resulted in estimating that these eggs are fertile.

Previous studies evaluating conditions affecting semen stored for $24 \mathrm{~h}$ have relied on fertility data that do not indicate the selection/storage ability of spermatozoa within the hen. The results of the present study show that about $80 \%$ fewer spermatozoa are embedded in the perivitelline layer after insemination with semen stored in vitro compared with fresh semen, resulting in lower fertility. The perivitelline layer bioassay was important for evaluating the effects of sperm storage conditions in vitro on subsequent selection and storage in the SST and fertility. Determining how spermatozoa are compromised in vitro and how this relates to reduced sperm storage in hens is essential for improving the use of stored semen in AI programmes.

The authors thank W. Smoot, D. Buschling and his staff for semen collection and animal care.

\section{References}

Alexander AA, Graham J, Hammersted RH and Barbato GF (1993) Effects of genotype and cryopreservation of avian semen on fertility and number of perivitelline spermatozoa British Poultry Science 34 757-764

Bakst MR (1992) Observations on the turkey oviductal spermatozoa-storage tubule using differential interference contrast microscopy Journal of Reproduction and Ferfility $96877-883$

Bakst MR (1993) Oviductal spermatozoa storage in poultry: A review Journal of Reproduction. Fertility and Development 5 595-599

Bakst MR and Cecil HC (1983) Gross appearance of turkey cloacae before and after single or multiple manual semen collections Poultry Science 62 683-689

Bakst MR and Cecil HC (1991) Effect of modifications of semen diluent with cell culture serum replacements on fresh and stored turkey semen quality and hen fertility Poultry Science 71 754-764

Bakst MR, Cecil HC and Sexton TJ (1991) Modification of the ethidium bromide exclusion procedure for evaluation of turkey semen Poultry Science $\mathbf{7 0}$ $366-370$

Bakst MR, Wishart G and Brillard JP (1994) Oviductal spermatozoa selection, transport, and storage in poultry Poultry Science Reviews 5 117-143

Brillard JP (1992) Factors affecting oviductal spermatozoa storage in domestic fowl following artificial insemination Animal Reproduction Science 27 $247-256$

Brillard JP (1993) Spermatozoa storage and transport following natural mating and artificial insemination Poultry Science 72 923-928 
Brillard JP and Antoine H (1990) Storage of spermatozoa in the uterovaginal junction and its incidence on the numbers of spermatozoa present in the perivitelline layer of hens' eggs British Poulty Science 31 635-644

Brillard JP and Bakst MR (1990) Quantification of spermatozoa in the spermatozoa-storage tubules of turkey hens and the relation to spermatozoa numbers in the perivitelline layer of eggs Biology of Reproduction 43 271-275

Christensen VL and Johnston NP (1977) Effect of time of day of insemination and the position of the egg in the oviduct on the fertility of turkeys Poultry Science $56 \quad 458-462$

Donoghue AM, Garner DL, Donoghue DJ and Johnson LA (1995) Determination of membrane integrity of fresh and $24 \mathrm{hr}$ stored turkey sperm using a combination of hypoosmotic stress, fluorescent staining and flow cytometry Journal of Andrology 1644

Froman DP and Thurston RJ (1984) Decreased fertility resulting from treatment of fowl spermatozoa with neuraminidase or phospholipase C Poultry Science $632479-2482$

McIntyre DR and Christensen VL (1985) Effect of initial insemination interval on fertility in turkey hens Poultry Science 64 1549-1552

SAS Institute (1985) SAS User's Guide. SAS Analysis System Institute Inc., Cary, NC

Sexton TJ (1988) Comparison of commercial diluents for holding turkey semen 24 hours at $5^{\circ} \mathrm{C}$ Poultry Science $67 \quad 131-134$
Steele MG (1992) A study of the influence of sperm surface proteins on the activity of avian spermatozoa in vitro and in vivo $\mathrm{PhD}$ Thesis, Dundee Institute of Technology

Thurston RJ (1995) Storage of poultry semen above freezing for 24-48 hours Proceedings of the First International Symposium on Artificial Insemination in Poultry pp. 107-122 Eds MR Bakst and H Cecil. Poultry Science Association, Savoy, IL

Van Krey HP, Leighton AT and Potter LM (1967) Spermatozoa gland populations and late seasonal decline in fertility Poultry Science $\mathbf{4 6} 1332$

Wishart GJ (1987) Regulation of the length of the fertile period in the domestic fowl by numbers of oviductal spermatozoa, as reflected by those trapped in laid eggs Journal of Reproduction and Fertility 80 493-498

Wishart GJ and Staines HJ (1995) Assessing the breeding efficiency of broiler breeder flocks by measuring sperm transfer into laid eggs British Poultry Science 36 317-323

Wishart GJ and Steele MG (1990) The influence of sperm surface characteristics on sperm function in the female reproductive tract. In Control of Fertility in Domestic Birds pp 101-112 Ed JP Brillard. Les Colloques de I'INRA, Tours

Wishart GJ, Staines HJ and Steele MG (1993) A method for predicting impending infertility in naturally-mated chickens and demonstration of gross variation in spermatozoa transfer efficiency Proceedings of the 19th World Poultry Congress Vol 1 631-634 